\title{
Factors affecting student-teacher satisfaction with a multi- college online collaborative course
}

\author{
Miri Shonfeld \\ Technology in Education Program, Kibbutzim College of Education, Israel
}

\begin{abstract}
This study examined the factors that may promote student-teachers' satisfaction with online collaborative learning (OCL). Eighty-four student teachers at the graduate level at three teacher-education colleges in Israel simultaneously completed questionnaires that examined their information and communication technology (ICT) skills, collaboration experience and personality traits. The findings reveal that ICT level, positive experiences with collaborative learning and openness contributed significantly to satisfaction with the collaborative project and accounted for $63 \%$ of the variance. Personal traits were found to be mediated by ICT level, and ICT level was in turn mediated by collaborative experience. The results demonstrate the importance of ICT level as a prerequisite for these courses and the significance of preparing the groups and structuring the activities to achieve positive collaborative experiences.
\end{abstract}

Implications for practice or policy:

- University stakeholders may build OCL courses in collaboration with other universities.

- University staff can determine how personality issues and ICT level affect students' success in OCL courses.

- Policymakers can better understand the preparation necessary to develop OCL courses.

- This case can help educators improve their collaborative programs.

Keywords: online collaborative learning (OCL), online learning, teacher education, personal traits, information and communication technology (ICT), qualitative

\section{Introduction}

The accelerated development of innovative technologies has created a new culture of digital communication and collaboration that shapes individuals, society and education (Johnson et al., 2014; Passey et al., 2018). Universities and colleges are increasingly demanding the use of technology in academic learning (KumiYeboah, 2018; Lambert et al., 2014). However, the assimilation of technologies in institutions of higher education involves extensive organisational and pedagogical changes (Amirault, 2012). Integrating online collaborative learning (OCL) into education systems, a new learning theory for the 21 st century, faces additional barriers (Harasim, 2012). Students' satisfaction with a course influences the learning process (Katz \& Yablon, 2009) and their decision to attend the program (Butt \& Rehman, 2010; Zhou, 2017). Thus, it is important to examine the factors that promote satisfaction with OCL courses.

Satisfaction is based on a range of elements. It is especially important to examine satisfaction within the team when examining OCL, since performance in learning increases when satisfaction with the group is higher (Lester et al., 2002). Similarly, it has been shown that social interaction, which is inherent in collaborative learning (CL), increases satisfaction with online learning (Horzum, 2015). In addition, interactive online learning promotes collaboration, which is increasingly important in the 21st century (Hesrcu-Kluska, 2019; Shonfeld \& Gibson, 2019).

The world is now in an age of global collaboration, characterised by the demand for technological skills (Cook et al., 2016; Shonfeld \& Gibson, 2019). The COVID-19 situation has moved students and faculty to online learning, where the need for student and faculty collaboration is critical (Neuwirth et al., 2020).

The importance of direct experience with online collaboration in teacher training is therefore highlighted. OCL can lead to improved attitudes towards technology, thus promoting teachers' engagement with the digital world (Hue \& Ab Jalil, 2013; Magen-Nagar \& Shonfeld, 2018; Zygouris-Coe, 2019). The pedagogical knowledge of teachers with positive attitudes towards technologies affects their teaching strategies and their willingness to introduce changes in their work (Shamir-Inbal \& Kali, 2011). 
This paper describes an exploratory study on OCL in graduate courses and its impact on student-teachers' attitudes towards OCL. These students experienced the technology, education and cultural diversity (TEC) model (Shonfeld et al., 2013), which is a unique form of OCL. In the TEC model, the students work online on their learning projects in small heterogeneous groups with students from different institutions and cultures. Thus, satisfaction with OCL is of great importance.

The findings may provide significant information for understanding the processes and factors involved in the success of collaborative models in higher education and their effect on student attitudes. The assumption was that teaching experience (seniority), information and communication technology (ICT) level, personal traits and positive experience in a group can predict satisfaction with OCL. The following subsections present the theoretical background for the following research variables: OCL, satisfaction and personality traits.

\section{Literature review}

\section{OCL}

CL has five components: positive interdependence, personal accountability, advanced interaction, social skills and group process (Johnson \& Johnson, 2017). When these components are effectively incorporated during instruction, the academic achievements, involvement, responsibility and motivation of learners can be improved (Hanze \& Berger, 2007). OCL is similar to collaborative face-to-face learning, but online meetings between group members can be both synchronous and asynchronous. Early research on asynchronous collaboration has found that online collaboration is more effective than face-to-face collaboration in terms of learning, the quality of problem-solving, the content of the solution and satisfaction with the quality of the solution (Tsuei, 2011). However, students were significantly less satisfied with asynchronous learning than with synchronous learning in terms of the group interaction process and the quality of group discussions (Ocker \& Yaverbaum, 1999).

OCL theory developed with the spread of online learning in higher education (Harasim, 2012). When learning in an online course is done through written texts, pictures and videos, there is a lack of social presence, and the student may feel isolated. OCL in online courses is therefore valuable because it promotes a sense of social presence (Shonfeld et al., 2013). This feeling contributes to the improvement of learning, motivation, satisfaction and students' ability to integrate different teaching methods (Abedin, 2012; Harasim, 2012). As a result, OCL has become one of the most widely used methods of distance learning.

Instructors increasingly value the importance of CL, but it is important that they adapt their pedagogy to suit it (Kumi-Yeboah, 2018; Shonfeld, 2017). There are differences between teachers in basic education who adopt CL (Krečič, \& Grmek, 2008) and those who do so at the post-secondary level (Shonfeld et al., 2019).

\section{Satisfaction}

Satisfaction is an important factor in motivating the individual to act and behave in a specific manner (Deci \& Ryan, 1985). Student satisfaction is defined as a subjective assessment of the students' results and experiences in education and in life on campus (Elliott \& Shin, 2002). Research examining student satisfaction in higher education has shown that instructors, the quality of instruction, methods and course administration are key elements (Aldemir \& Gulcan, 2004; DeShields et al., 2005).

The research literature on distance learning has presented an inconsistent variety of indicators to test student satisfaction with learning. These indicators have three aspects: psychological factors, such as a sense of ability and pleasure; pedagogical approaches, such as teaching methods; and course structure, such as the communication medium (So \& Brush, 2008). Interaction is another factor that influences satisfaction with online learning environments (Ali et al., 2011; Lee \& Rha, 2009).

Interaction in online courses contributes to higher satisfaction and reduces dropout (Croxton, 2014). Thus, collaboration that encourages interaction might contribute to student satisfaction in online learning. Ku et al. (2013) found that team satisfaction in OCL is affected by team commitment, communication among team members, interactive software and synchronous meetings. However, different characteristics of 
learners, such as age, familial responsibilities as well as different cultures can affect their satisfaction with OCL (Zhu, 2012). For example, Flemish students showed more satisfaction than Chinese students as a result of their different perceptions of learning processes. Satisfaction can be affected by the quality of the instruction, academic support, library services, usability of the course website, communication services, Internet speed, quality of course materials and student interest. Student satisfaction is likely to be increased by an intervention program that integrates OCL (Horzum, 2015).

The present study suggests that an intervention model of using collaborative online methodology can contribute to promoting satisfaction. Effective professional development will involve practical intervention designed to change approaches to knowledge acquisition as well as to the implementation of innovative teaching. The teacher serves as a facilitator, and the students are the source of knowledge (C. Kim et al., 2013).

\section{Personality traits}

Weinberger and Shonfeld (2018) found that students' perception of OCL included active involvement, social interactions and dialogic processes that enable the construction of knowledge, in accordance with social constructivism. Those perceptions might be a result of the students' experiences of OCL but also of their personalities.

The big five model is one of the best-known measures of personality structure that have become popular in recent years (Golbeck et al., 2011) and is used in online environments as well (Picazo-Vela et al., 2010; Zhang et al., 2020). This comprehensive model consists of five major factors representing personality traits: neuroticism, extraversion, agreeableness, openness to experience and conscientiousness. Each factor in the model is bipolar and contains different aspects. Research has examined the model, finding high validity and reliability across gender, age and cultural lines (McCrae \& John, 1992).

According to J. L. Wang et al. (2012), neuroticism contrasts with emotional stability and is characterised by anxiety, sadness, irritability, moodiness, hostility and nervous tension. Extraversion is associated with activity, energy, assertiveness, sociability, talkativeness, expressiveness and positive emotions. Agreeableness consists of altruism, warmth, trust, modesty, cooperativeness and tendermindedness. Openness to experience addresses the complexity and depth of the person's mental and experiential life and consists of curiosity, creativity and preference for novelty. Conscientiousness refers to impulse control that contributes to task- and goal-directed behaviour and is associated with discipline, reliability, responsibility and organisation.

Various studies have examined the connection between the big five model (Caprara et al., 1993) and Internet use (Amichai-Hamburger, 2002; Amichai-Hamburger et al., 2002) and have shown that extraversion is significantly related to Internet use. Mark and Ganzach (2014) have suggested that global Internet use is positively related to extraversion and conscientiousness. Another study has focused on the relationship between the big five model and the use of social network sites, showing that they are related (Selfhout et al., 2010). However, several studies have proposed that extraversion is the dominant factor (Aharony, 2013; Gosling et al., 2011). In addition, Deng et al. (2013) found that extraversion impacts perceived satisfaction from supplementary entertainment.

Personality traits are good predictors of satisfaction with online courses (Cohen \& Baruth, 2017). Therefore, it is reasonable to examine them as predictors of satisfaction with OCL. Rahman (2014), for example, found a correlation between conscientiousness, extraversion and openness, and motivation among students in higher education. For this reason, the present research examined these personality traits in relation to satisfaction with OCL.

\section{The research}

\section{The intervention program}

As part of the graduate programs at three colleges of education in Israel, an innovative curriculum was developed by the instructors, based on collaboration in distance learning among their students. During the second semester of the 2017 academic year, three classes of graduate students - educational technology 
students from Tel Aviv, educational technology students from the south and students from programs in teaching and learning from the north - participated in a 10-week study. Online collaborative groups comprised students from the participating colleges, using the TEC model (Shonfeld et al., 2013). The TEC model incorporates innovative technology in teaching and learning processes in a multicultural environment. It suggests that group work via the Internet be done through text-based forums, where the students do not see or hear each other. A gradual change in the forms of communication - first, the addition of audio and then video - strengthens the trust between the groups. According to the model, CL gradually develops through the joint execution of tasks, from the dialogue stage to the synergistic collaboration stage with the use of both simple and complex network tools. The three classes were divided into groups which consisted of students from all the participating institutions (see Figure 1). The instructors collaborated to develop the online lessons. In addition, each of them moderated five student groups (with each group consisting of six students).

\section{From Homogenous Classes to Heterogeneous Virtual Groups}

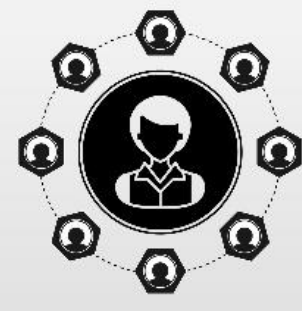

Class 1

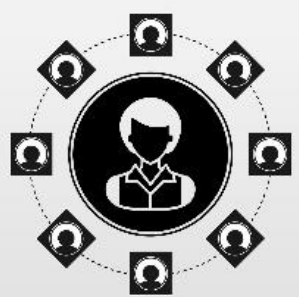

Class 2

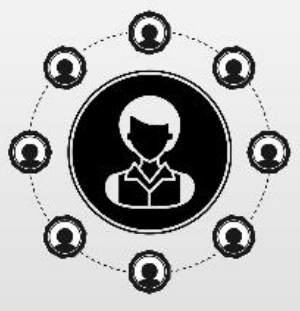

Class 3

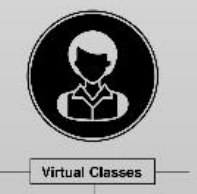

$\begin{array}{lll}0 & 0 & 0 \\ 0 & 0 & 0 \\ 0 & 0 & 0 \\ 0 & 0 & 0 \\ 0 & 0 & 0 \\ 0 & 0 & 0\end{array}$

(9)
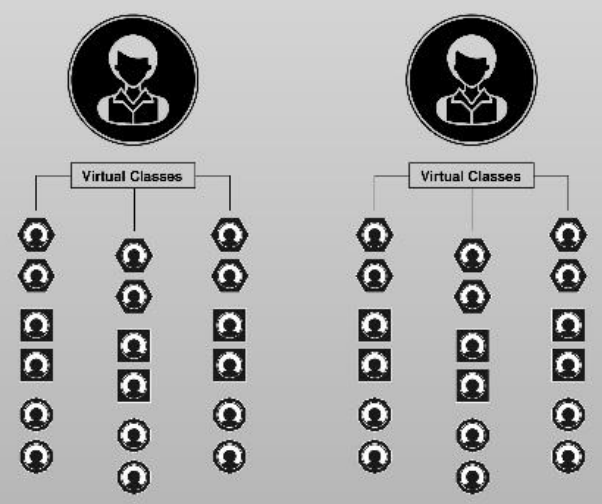

Figure 1. The process of creating heterogeneous groups

The intervention program was designed to expose students to the field of distance learning and issues unique to this particular learning process, to impart knowledge and to provide experience and in-depth knowledge in this field. The intervention encouraged the development of research and collaborative skills and analytical thinking in an online environment. The inquiry processes were based on reading, discussions, interviews and collaborative writing, using collaborative technology tools in a Moodle environment, such as the group blog, group discussions, group pages and synchronous meetings such as Blackboard Connect. The inquiry process was performed in six stages defined in time units. Some involved teamwork, while others required individual learning. 
The group-learning process was based on research which students conducted collaboratively. First, each group raised ideas or concepts close to the chosen topic. The second step included searching for information, reading and summarising. The third step focused on formulating research questions. Thereafter, online interviews were conducted, with each student interviewing one of the group members and being interviewed by another. The students summarised the interviews and the literature and planned the related activities. After completing the unit, students were given the opportunity to review and evaluate a unit of another group. The level of cooperation required was low initially, but by the end of the learning period there was a high level of CL (Salmons, 2019) such as parallel CL, sequential CL and even synergetic $\mathrm{CL}$ when the students were required to build a learning unit. While working with the students in the collaborative course, the instructors obtained a diverse picture of their satisfaction with the project. Hence, it was interesting to understand the reasons for the variance in students' level of satisfaction.

In light of the above, the research questions were:

- To what extent do the students' demographic variables explain their satisfaction with CL experiences?

- To what extent does the students' ICT level explain their satisfaction with CL experiences?

- To what extent do personality characteristics derived from the big five personality traits model explain student-teachers' satisfaction?

- To what extent does collaboration in the learning group explain student-teachers' satisfaction with the project?

\section{Research hypotheses}

The current study focused on ICT level, experience in teaching (seniority), experience with OCL (collaboration) and three of the big five characteristics - openness to experience, extraversion and conscientiousness - assuming that those variables might predict students' level of satisfaction with the collaborative project. The underlying assumptions and hypotheses of this study were:

- H1: A high level of ICT competence will be positively associated with student-teachers' satisfaction with collaborative experiences.

- H2: Extraversion and openness to experience will be positively associated with student-teachers' satisfaction with collaborative experiences.

- H3: Conscientiousness will be negatively associated with student-teachers' satisfaction with collaborative experiences.

- H4: A positive collaborative experience in the project will be positively associated with studentteachers' satisfaction with this type of learning.

\section{Methodology}

\section{Participants}

The research participants consisted of students from three classes enrolled in graduate programs in three institutions in Israel. Of the 92 students who were enrolled in an online course, 84 completed a survey after finishing a high-level CL project - 23 at the college in Tel Aviv, 31 at the northern college and 30 at the southern college. The sample of 84 consisted of 77 women $(91.7 \%)$ and seven men (8.3\%). The average age was 39.67, with the youngest aged 27 and the oldest aged 59. The average years of teaching (seniority) was 14.3; the least experience was one year and the most 38 years. Since the correlation between age and seniority was high (.87), only one of these two factors was analysed. As seniority is an important factor in improving teaching and learning competencies, only the seniority variable was analysed with regard to satisfaction in the present study.

\section{Instruments}

The research was based on a post-course survey. The self-report survey contained five topics that were covered by five combined questionnaires: personal details, collaboration experience, satisfaction with the collaborative project, ICT level and personality traits. The personal details section had four parameters: 
college, seniority, gender and age. The collaboration experience questionnaire consisted of 19 statements rated on a five-point Likert scale (from $1=$ strongest disagreement to $5=$ strongest agreement). This questionnaire was based on the Waters and Napier (2002) collaboration model and contained statements regarding the possible challenges of collaborative work, such as "My team members know their role" and "My team members share their experiences." The Cronbach's alpha value was .96.

The satisfaction questionnaire was based on Tseng et al. (2009). It consisted of 10 questions, such as "I have benefited from my team feedback" and "I like working in a collaborative group with my teammates." These statements were rated on a five-point Likert scale (from $1=$ strongest disagreement to $5=$ strongest agreement). The Cronbach's alpha value was .96.

The ICT level questionnaire consisted of six statements rated on a five-point Likert scale $(1$ = strongest disagreement; 5 = strongest agreement). This questionnaire was based on that of Goldstein and Tessler (2017) and contained statements about using technology. The Cronbach's alpha value was .87.

The personality questionnaire was based on the big five personality traits (John et al., 1991) and was modified for this study. Since the complete survey might have been too lengthy, it was shortened. Three professionals in this area decided which of the statements should be removed. Based on Rahman's (2014) results, only three of the personality traits were chosen to be examined for their contribution to satisfaction with CL. The revised survey contained 24 statements rated on a five-point Likert scale $(1=$ strongest disagreement; 5 = strongest agreement), which were considered to be the most important contributing personality traits. The questionnaire consisted of three factors: extraversion (eight items), conscientiousness (nine items) and openness to experience (seven items). The Cronbach's alpha values were .78, .68, and .81 respectively.

\section{Procedure}

After having finished studying in a heterogeneous collaborative group and completing collaborative tasks, the students from the three colleges were asked to complete a self-report survey regarding their personal characteristics and course experience. Permission to undertake the study was obtained from the research unit of each college. The survey was displayed online using Google Forms, and the time allotted to complete the survey questions was approximately 15 minutes. The results were transferred from Google Forms to Excel, converted to an SPSS file and then analysed using descriptive statistics, Pearson correlations and hierarchical regression.

\section{Results}

The aim of this study was to examine the reasons for the variance in students' satisfaction with an online collaborative project in an online course. The participants were graduate students studying with OCL methodology according to the TEC model. The assumption was that seniority and the level of ICT would affect satisfaction with the project. Personality traits were assumed to be a contributor to satisfaction, ICT level and collaboration level, as would the type of institution.

In order to examine whether there were differences in satisfaction among the students from the different institutions, a one-way MANOVA was performed. The MANOVA revealed no significant difference between the groups, $F(14,150)=1.75, p>.05$. Therefore, the analysis of variance for the differences in satisfaction was performed for all participants together.

Descriptive statistics from the questionnaire results indicate that these populations' satisfaction was at the level of $M($ mean $)=3.54$ and $S D$ (standard deviation $)=.98$, where the mean was measured on a scale of 1-5. This indicates that the students' satisfaction was above average but not high. The level of collaboration was lower, $M=3.08$ and $S D=.92$, as was their ICT level, $M=3.21$ and $S D=.95$. They had many years of teaching experience (seniority), $M=13.69$ and $S D=7.36$.

The relationships between collaboration, seniority, personality characteristics, ICT level and the dependent variable (satisfaction) were examined using Pearson correlations, and are presented in Table 1. 
Table 1

Pearson correlations between satisfaction and research variables $(N=84)$

\begin{tabular}{|c|c|c|c|c|c|c|}
\hline Measures & Seniority & Extraversion & Conscientiousness & Openness & ICT level & Collaboration \\
\hline Extraversion & $.26 * *$ & & & & & \\
\hline Conscientiousness & .11 & $.47 * * *$ & & & & \\
\hline Openness & .20 & $.61 * * *$ & $.40^{\star * *}$ & & & \\
\hline ICT level & $42 * *$ & $.26 *$ & .06 & $.27 *$ & & \\
\hline Collaboration & -.02 & $.25^{*}$ & .12 & $.44 * * *$ & .14 & \\
\hline Satisfaction & .13 & $.28 * *$ & $.23^{*}$ & $.46 * * *$ & $.30 * *$ & $72 * * *$ \\
\hline
\end{tabular}

$* p<.05, * * p<.01, * * * p<.001$

Table 1 shows significant correlations between almost all the research variables and the dependent variables (satisfaction). Significant positive correlations were found between seniority and extraversion level and ICT level. In other words, the more experienced the student-teachers (higher seniority), the higher the extraversion and ICT levels. Level of extraversion is correlated with all research variables. Therefore, the more extraverted the students were, the higher their openness to experience and their conscientiousness. The higher the extraversion, the higher the ICT level, collaboration and satisfaction. However, conscientiousness is correlated only with openness and satisfaction. Openness is correlated with ICT level, collaboration and satisfaction. Hence, the higher the openness, the higher the ICT level as well as collaboration and satisfaction. In addition, the higher the ICT level, the higher the satisfaction. There is also significant correlation between collaboration and satisfaction.

I also conducted a hierarchical regression analysis in which the dependent variable was satisfaction. The regression explained $63 \%$ of the explained variance of satisfaction. The predictors were entered in four steps: (a) demographic details (seniority); (b) ICT level; (c) personality characteristics (openness to experience, extraversion, and conscientiousness); and (d) collaboration. In the regression analysis, the entry of the first four steps was forced, and no interaction was found between the research variables. Table 2 presents the standardised and unstandardised coefficients of the hierarchical regression of respondents' satisfaction).

Table 2

Hierarchical regression coefficients of respondents' satisfaction $(N=84)$

\begin{tabular}{llllll}
\hline Step & Predictors & $\mathrm{B}$ & $\beta$ & $\mathrm{R}^{2}$ & $\Delta \mathrm{R}^{2}$ \\
\hline 1. & Seniority & .18 & .14 & .02 & .02 \\
\hline 2. & Seniority & .17 & .13 & $.22^{* *}$ & $.19^{* *}$ \\
& ICT level & .31 & $.30^{* *}$ & & \\
\hline 3. & Seniority & .00 & .04 & $.26^{* *}$ & $.15^{* *}$ \\
& ICT level & .21 & $.21^{*}$ & & \\
& Extraversion & -.10 & -.06 & & \\
& Conscientiousness & .16 & .08 & & \\
& Openness & .61 & $.40^{* *}$ & & $.37^{* * *}$ \\
& Seniority & .01 & .10 & $.63^{* * *}$ & \\
& ICT level & .18 & $.17 *$ & & \\
& Extraversion & -.23 & -.14 & & \\
& Conscientiousness & .16 & .08 & & \\
& Openness & .40 & $.26^{* *}$ & & \\
& Collaboration & .69 & $.64 * * *$ & & \\
& C. & & &
\end{tabular}

$* p<.05, * * p<.01, * * * p<.001$

The first step introduced seniority and found that the contribution was not significant. The second step introduced the ICT level, which contributed $19 \%$ to the explained variance of satisfaction with the collaborative experiences.

The third step, personality characteristics (openness, extraversion, conscientiousness) was inserted and added $15 \%$ to the explained variance of satisfaction. Of the three personality traits, only openness contributed significantly. In other words, the more open to experience students were, the higher their satisfaction. In the third step, where personality traits (openness, extraversion, conscientiousness) were inserted, it caused a decrease in the $\beta$ coefficient for the ICT-level variable from step two $(\beta=.30, p<.01)$ 
to step three $(\beta=.21, p<.05)$. Therefore, we may conclude that personality traits are mediators; that is, that as students gain more confidence in using ICT, their openness to experience increases, which then increases their satisfaction. In the Sobel analysis test for significant mediation, it was found that the mediator is openness, where the Sobel result was significant $(Z=2.10, p<.05)$. It can be concluded that when the ICT level is higher, the openness is higher, and when the openness is higher, so is the satisfaction.

The fourth step introduced collaboration, which contributed significantly by adding $37 \%$ to the explained variance of ICT level. The $\beta$ coefficient of collaboration was positive; hence, the greater the students' collaboration in the group, the greater their satisfaction with the collaborative project. In the fourth step, where collaboration was inserted, it caused a decrease in the $\beta$ coefficient for the personality trait of openness. The $\beta$ coefficient of openness in step three was $\beta=.40(p<.01)$ and decreased in step four to $\beta$ $=.26(p<.01)$. Therefore, collaboration appears to serve as a mediator for the personality trait of openness. The Sobel analysis test for significant mediation showed that the collaboration mediation to openness was significant $(\mathrm{z}=2.62, p<.01)$. It can be concluded that when openness is higher, collaboration is higher, and when collaboration is higher, satisfaction is higher.

\section{Discussion}

CL has become a recommended method of online learning (Harasim, 2012; Hue \& Ab Jalil, 2013) and learning in heterogeneous groups in the 21st century (Barak, 2018; Cook et al., 2016; Shonfeld \& Resta, 2019). The experience of OCL improves approaches towards technology (Hue \& Ab Jalil, 2013; MagenNagar \& Shonfeld, 2018), which in turn affects teaching strategies (Shamir-Inbal \& Kali, 2011). Satisfaction with learning positively influences the learning process (Callaghan et al., 2013; Katz \& Yablon, 2009; Zhou, 2017) and participation in programs in higher education (Butt \& Rehman, 2010). Thus, it is important to achieve high satisfaction in new teaching and learning methods. In addition, performance in learning increases when satisfaction within the group is higher (Lester et al., 2002).

The current study therefore aimed to examine the factors that influence and improve satisfaction with OCL methodology. The results revealed that ICT level, openness to experience and collaboration experience contributed significantly to satisfaction with the collaborative project and accounted for $63 \%$ of the variance. This is in line with other research that has found that student satisfaction increases with an intervention program that integrates OCL (Horzum, 2015).

It seems that satisfaction with OCL and ICT level have a reciprocal relationship. On the one hand, satisfaction with a course influences the integration of technology in teaching and teacher attitudes (Katz \& Yablon, 2009); on the other, as presented in this study, ICT level positively influenced the level of satisfaction. It should be mentioned that this is contrary to the literature that has shown no significant correlations between students' satisfaction with OCL and their computer literacy (Kitchen \& McDougall, 1999). This might be because previous research was conducted in a different OCL environment, where interaction was limited to asynchronous technology, while this study included a more advanced level of ICT and produced better results in terms of social interactions and positive experiences in the groups. It could also be due to different teacher educator populations when comparing this study to other research studies. What is clear is that integration of ICT into OCL programs is vital to the success of projects (KumiYeboah, 2018).

ICT level was found to contribute to satisfaction and was moderated by the factor of openness. This might be explained by the fact that in order to gain a high level of ICT, one has to be open to experiences. This is in accordance with research that has shown that ICT-proficient students are more inclined to listen to diverse opinions and less inclined to do the same things repeatedly (Barak, 2018). Students who are openminded and curious about new experiences are likely to be interested in performing unconventional tasks that allow them to discover other ways of thinking. Such students will be more satisfied with activities that include collaboration with students from other colleges and cultures.

The assumption that extraversion and openness to experience would be positively associated with studentteachers' satisfaction with collaborative experiences was strengthened. There was a correlation between extraversion and openness to collaboration and satisfaction. A high level of openness to experience and extraversion might contribute to interaction among group members, and since interaction is a factor that 
influences the satisfaction in online learning (Ali et al., 2011; Lee \& Rha, 2009), it might also be effective in OCL. However, only openness contributed significantly to the explanation of the variance in satisfaction. Openness was found to be an important trait differentiating between teachers participating in digital projects and those who did not participate. It was also found to be a factor that contributed significantly to the explanation of the variance in perceived information literacy (Kritz, 2019). It seems that those who are open-minded and curious will be open to ICT and acquire better skills as well as connect more with their group members via OCL platforms. The use of social networks, blogs and other social platforms contributes to openness; and thus, ICT level leads to openness. Openness, as explained, contributes to better online collaboration and therefore to moderating the impact of ICT level.

The greatest contribution to the student-teachers' satisfaction was the experience of collaboration within the group. This concurs with the findings of Johnson and Johnson (2017), who emphasised group process as one of the conditions of success in CL. Sleeman et al. (2019) demonstrated that students who engaged in collaborative interactions via social media were more likely to perceive a connection to their classmates. This has implications for educators to include classroom modelling of digitally mediated collaborative interactions to benefit students' participation in group assignments, which can improve the transition experience through social connection. Group process influenced by interaction was a factor that influenced satisfaction in online learning environments (Ali et al., 2011; Croxton, 2014; Lee \& Rha, 2009). To conclude, research emphasises the importance of a positive experience with OCL to the success of the course. Thus, OCL pedagogy has to be taken into account in online programs in higher education.

These findings could guide educators and policymakers in designing and conducting successful OCL programs that utilise elements which increase learners' satisfaction. The importance of examining personality traits and student-teacher satisfaction can assist university staff in constructing OCL courses and understanding and evaluating the outcomes. Moreover, this sheds light on the need to find alternative ways to support learners with more introverted characteristics. Educators and researchers should focus on effective ways of allowing such students to engage in OCL courses in a manner that accommodates their needs both socially and technologically. The role of university staff would then be to identify and target those requiring additional support. By modelling and highlighting these processes as part of teacher training, student-teachers may be better able to adjust and apply them in their work to achieve positive OCL outcomes.

\section{Limitations and future research}

This research was limited to graduate students in Israel. I recommend replicating it using a larger population, conducting interviews with the student-teachers involved and distributing questionnaires and using mixed methods to acquire a deeper understanding of the effects of OCL. It should also be conducted with undergraduate students who study other subjects. The research was further limited by the length of the project, the number of students participating and the number of colleges and cultures. Thus, subsequent research should include larger and more diverse student populations and courses. ICT level as well as personality traits such as openness, in addition to good collaborative experiences, promote satisfaction with OCL programs. Yet, apart from the personality traits of the individual members, the dynamics of their interactions and the factors that influence them, such as the composition of the group (D. Y. Wang et al., 2007) and the learning environment, are worth closer examination.

This research deals with the specific environments of Moodle and Blackboard Connect. However, different kinds of OCL environments can promote different aspects of OCL. Three-dimensional multi-user virtual environments can facilitate student learning and collaboration and enhance social presence in group meetings as part of collaborative work. Together with voice communication, multi-user virtual environments enable the group members to exchange ideas in an authentic environment and reinforce CL. As long as technical problems are avoided, effective CL can be achieved in these environments (Shonfeld \& Resta., 2019; Tüzün et al., 2019). Therefore, it is recommended that adopters discover which factors promote satisfaction in different environments.

In order to motivate students, it is recommended that they be involved in cross-cultural, CL projects (KumiYeboah, 2018). Given that multicultural collaboration has become increasingly important in today's world, the roles that cultural differences and language differences play as barriers to trust development and satisfaction with OCL should be examined closely. Language differences may inhibit communication and 
thus influence the development of trust in mutual interactions. In addition, different cultural values and habitual behaviours appear to be influential (Cheng et al., 2016). This was not examined in this study, but it should be part of future research.

With regard to OCL, follow-up research could examine more deeply the factors that influence the perception of good online collaboration. For instance, as highlighted by Cheng et al. (2016), the development of trust among the group members appears to play a critical role. To investigate trust development, longitudinal research is clearly needed, particularly since trust shifts dynamically depending on a variety of factors (Cheng et al., 2013).

\section{Conclusion}

This study revealed that ICT level, openness to experience and positive collaboration experience contributed significantly to satisfaction with the collaborative project. Therefore, investing in developing students' ICT skills as a prerequisite to having them enrol in OCL courses is recommended. When this is not possible, such an investment can be embedded into the beginning of the course as part of the collaborative tasks. In addition, preparing them to work in and learn in groups might improve their satisfaction with and success in those courses, which are becoming increasingly widespread in higher education.

\section{References}

Abedin, B. (2012). Sense of community and learning outcomes in computer supported collaborative learning environments. Proceedings of International Conference on Business and Information (BAI 2012), 9(1), 964-969.

Aharony, N. (2013). Factors affecting the adoption of Facebook by information professionals. Proceedings of the American Society for Information Science and Technology, 50(1), 1-10. https://doi.org/10.1002/meet.14505001030

Aldemir, C., \& Gulcan, Y. (2004). Student satisfaction in higher education: A Turkish case. Higher Education Management and Policy, 16(2), 109-122. https://doi.org/10.1787/hemp-v16-art19-en

Ali, A., Ramay, M. I., \& Shahzad, M. (2011). Key factors for determining student satisfaction in distance learning courses: A study of Allama Iqbal Open University (AIOU), Islamabad, Pakistan. Turkish Online Journal of Distance Education, 12(2), 114-127. https://dergipark.org.tr/en/pub/tojde/issue/16904/176256

Amichai-Hamburger, Y. (2002). Internet and personality. Computers in Human Behavior, 18(1), 1-10. https://doi.org/10.1016/S0747-5632(01)00034-6

Amichai-Hamburger, Y., Wainapel, G., \& Fox, S. (2002). “On the Internet no one knows I'm an introvert": Extroversion, neuroticism, and Internet interaction. Cyberpsychology \& Behavior, 5(2), 125-128. https://doi.org/10.1089/109493102753770507

Amirault, R. J. (2012). Distance learning in the 21st century university: Key issues for leaders and faculty. Quarterly Review of Distance Education, 13(4), 253-256.

Barak, M. (2018). Are digital natives open to change? Examining flexible thinking and resistance to change. Computers \& Education, 121, 115-123. https://doi.org/10.1016/j.compedu.2018.01.016

Butt, B. Z., \& Rehman, K. (2010). A study examining the students' satisfaction in higher education. Procedia-Social and Behavioral Sciences, 2(2), 5446-5450. https://doi.org/10.1016/j.sbspro.2010.03.888

Callaghan, D. E., Graff, M. G., \& Davies, J. (2013). Revealing all: Misleading self-disclosure rates in laboratory based on-line research. Cyberpsychology, Behavior, and Social Networking, 16(9), 690694. https://doi.org/10.1089/cyber.2012.0399

Caprara, G. V., Barbaranelli, C., Borgogni, L., \& Perugini, M. (1993). The "Big Five Questionnaire": A new questionnaire to assess the five factor model. Personality and individual Differences, 15(3), 281288. https://doi.org/10.1016/0191-8869(93)90218-R

Cheng, X., Fu, S., Sun, J., Han, Y., Shen, J., \& Zarifis, A. (2016). Investigating individual trust in semivirtual collaboration of multicultural and unicultural teams. Computers in Human Behavior, 62, 267276. https://doi.org/10.1016/j.chb.2016.03.093 
Cheng, X., Macaulay, L., \& Zarifis, A. (2013). Modeling individual trust development in computer mediated collaboration: A comparison of approaches. Computers in Human Behavior, 29(4), 17331741. https://doi.org/10.1016/j.chb.2013.02.018

Cohen, A., \& Baruth, O. (2017). Personality, learning, and satisfaction in fully online academic courses. Computers in Human Behavior, 72, 1-12. https://doi.org/10.1016/j.chb.2017.02.030

Cook, A. L., Bell, M. L., Nugent, J., \& Smith, W. S. (2016). Global collaboration enhances technology literacy. Technology and Engineering Teacher, 75(5), 20-25. https://www.iteea.org/Publications/Journals/TET/TETFebruary2016.aspx

Croxton, R. A. (2014). The role of interactivity in student satisfaction and persistence in online learning. Journal of Online Learning and Teaching, 10(2), 314-325. https://jolt.merlot.org/vol10no2/croxton 0614.pdf

Deci, E. L., \& Ryan, R. M. (1985). Intrinsic motivation and self-determination in human behavior. Springer. https://doi.org/10.1007/978-1-4899-2271-7

Deng, S., Liu, Y., Li, H., \& Hu, F. (2013). How does personality matter? An investigation of the impact of extraversion on individuals' SNS use. Cyberpsychology, Behavior, and Social Networking, 16(8), 575-581. https://doi.org/10.1089/cyber.2012.0383

DeShields, O. W., Jr., Kara, A., \& Kaynak, E. (2005). Determinants of business student satisfaction and retention in higher education: Applying Herzberg's two-factor theory. International Journal of Educational Management, 19(2), 128-139. https://doi.org/10.1108/09513540510582426

Elliott, K. M., \& Shin, D. (2002). Student satisfaction: An alternative approach to assessing this important concept. Journal of Higher Education Policy and Management, 24(2), 197-209. https://doi.org/10.1080/1360080022000013518

Golbeck, J., Robles, C., \& Turner, K. (2011). Predicting personality with social media. In D. Tan, B. Begole, \& W. A. Kellogg (Eds.), CHI'11: Extended Abstracts on Human Factors in Computing Systems (pp. 253-262). Association for Computing Machinery. https://doi.org/10.1145/1979742.1979614

Goldstein, O., \& Tessler, B. (2017). The impact of the national program to integrate ICT in teaching in pre-service teacher training. Interdisciplinary Journal of E-Skills and Lifelong Learning, 13, 151-166. https://doi.org/10.28945/3876

Gosling, S. D., Augustine, A. A., Vazire, S., Holtzman, N., \& Gaddis, S. (2011). Manifestations of personality in online social networks: Self-reported Facebook-related behaviors and observable profile information. Cyberpsychology, Behavior, and Social Networking, 14(9), 483-488. https://doi.org/10.1089/cyber.2010.0087

Hanze, M., \& Berger, R. (2007). Cooperative learning, motivational effects and student characteristics: An experimental study comparing cooperative learning and direct instruction in 12th grade physics classes. Learning and Instruction, 1(17), 29-41. https://doi.org/10.1016/j.learninstruc.2006.11.004

Harasim, L. (2012). Learning theory and online technology: How new technologies are transforming learning opportunities. Routledge Press. https://doi.org/10.4324/9781315716831

Hesrcu-Kluska, R. (2019). The interaction between learners and learner-facilitator in an online learning environment. Creative Education, 10(7), 1713-1730. https://doi.org/10.4236/ce.2019.107122

Horzum, M. B. (2015). Interaction, structure, social presence, and satisfaction in online learning. Eurasia Journal of Mathematics, Science \& Technology Education, 11(3), 505-512. https://doi.org/10.12973/eurasia.2014.1324a

Hue, L., \& Ab Jalil, H. (2013). Attitudes towards ICT integration into curriculum and usage among university lecturers in Vietnam. International Journal of Instruction, 6(2), 54-66. http://www.eiji.net/dosyalar/iji_2013_2_4.pdf

John, O. P., Donahue, E. M., \& Kentle, R. L. (1991). The Big Five Inventory--Versions $4 a$ and 54. University of California.

Johnson, L., Adams Becker, S., Estrada, V., Freeman, A. (2014). NMC Horizon Report 2014: Higher education edition. New Media Consortium. https://library.educause.edu//media/files/library/2014/1/hr2014-pdf.pdf

Johnson, D. W., \& Johnson, F. P. (2017). Joining together: Group theory and group skills (12th ed.). Pearson Education.

Katz, Y. J., \& Yablon, Y. B. (2009). Mobile learning: A major e-learning platform. In A. Szucs (Ed.), New Technology Platforms for Learning - Revisited: Proceedings of the LOGOS Open Conference on Strengthening the Integration of ICT Research Effort (pp. 121-128). European Distance and Elearning Network. 
Kim, C., Kim, M. K., Lee, C., Spector, J. M., \& DeMeester, K. (2013). Teacher beliefs and technology integration. Teaching and Teacher Education, 29, 76-85. https://doi.org/10.1016/j.tate.2012.08.005

Kitchen, D., \& McDougall, D. (1999). Collaborative learning on the Internet. Journal of Educational Technology Systems, 27(3), 245-258. https://doi.org/10.2190/5H41-K8VU-NRFJ-PDYK

Krečič, M. J., \& Grmek, M. I. (2008). Cooperative learning and team culture in schools: Conditions for teachers' professional development. Teaching and Teacher Education, 24(1), 59-68. https://doi.org/10.1016/j.tate.2007.02.011

Kritz, N. (2019). Tfisat ramat ha'mesugalut ha'atzmit shel oryanut ha'meyda etezel morim [Teachers' perceived information literacy self-efficacy] [Unpublished master's thesis]. Bar-Ilan University.

Ku, H. Y., Tseng, H. W., \& Akarasriworn, C. (2013). Collaboration factors, teamwork satisfaction, and student attitudes toward online collaborative learning. Computers in Human Behavior, 29(3), 922929. https://doi.org/10.1016/j.chb.2012.12.019

Kumi-Yeboah, A. (2018). Designing a cross-cultural collaborative online learning framework for online instructors. Online Learning, 22(4), 181-201. https://doi.org/10.24059/olj.v22i4.1520

Lambert, C., Erickson, L., Alhramelah, A., Rhoton, D., Lindbeck, R., \& Sammons, D. (2014). Technology and adult students in higher education: A review of the literature. Issues and Trends in Educational Technology, 2(1), 1-19. https://doi.org/10.2458/azu_itet_v2i1_lambert

Lee, H. J., \& Rha, I. (2009). Influence of structure and interaction on student achievement and satisfaction in web-based distance learning. Journal of Educational Technology \& Society, 12(4), 372-382. https://drive.google.com/file/d/1VD0UXMg37rVQ1XzhiX49sdMKtmb4zCkr/view

Lester, S. W., Meglino, B. M., \& Korsgaard, M. A. (2002). The antecedents and consequences of group potency: A longitudinal investigation of newly formed work groups. Academy of Management Journal, 45(2), 352-368. https://doi.org/10.5465/3069351

Magen-Nagar, N., \& Shonfeld, M. (2018). The impact of an online collaborative learning program on students' attitude towards technology. Interactive Learning Environments, 26(5), 621-637. https://doi.org/10.1080/10494820.2017.1376336

Mark, G., \& Ganzach, Y. (2014). Personality and Internet usage: A large-scale representative study of young adults. Computers in Human Behavior, 36, 274-281. https://doi.org/10.1016/j.chb.2014.03.060

McCrae, R. R., \& John, O. P. (1992). An introduction to the five-factor model and its applications. Journal of Personality, 60(2), 175-215. https://doi.org/10.1111/j.1467-6494.1992.tb00970.x

Neuwirth, L. S., Jović, S., \& Mukherji, B. R. (2020). Reimagining higher education during and postCOVID-19: Challenges and opportunities. Journal of Adult and Continuing Education. https://doi.org/10.1177/1477971420947738

Ocker, R. J., \& Yaverbaum, G. J. (1999). Asynchronous computer-mediated communication versus faceto-face collaboration: Results on student learning, quality and satisfaction. Group Decision and Negotiation, 8(5), 427-440. https://doi.org/10.1023/A:1008621827601

Passey, D., Shonfeld, M., Appleby, L., Judge, M., Saito, T., \& Smits, A. (2018). Digital agency: Empowering equity in and through education. Technology, Knowledge and Learning, 23(3), 425439. https://doi.org/10.1007/s10758-018-9384-X

Picazo-Vela, S., Chou, S. Y., Melcher, A. J., \& Pearson, J. M. (2010). Why provide an online review? An extended theory of planned behavior and the role of Big-Five personality traits. Computers in Human Behavior, 26(4), 685-696. https://doi.org/10.1109/WI-IAT.2013.70

Rahman, S. (2014). Effect of personality factor on achievement motivation. Indian Journal of Health and Wellbeing, 5(1), 40-45.

Salmons, J. E. (2019). Learning to collaborate, collaborating to learn: Engaging students in the classroom and online. Stylus Publishing.

Selfhout, M., Burk, W., Branje, S., Denissen, J., Van Aken, M., \& Meeus, W. (2010). Emerging late adolescent friendship networks and Big Five personality traits: A social network approach. Journal of Personality, 78(2), 509-538. https://doi.org/10.1111/j.1467-6494.2010.00625.x

Shamir-Inbal, T., \& Kali, Y. (2011). Model maarahti le'hatmaat tikshuv be'tarbut beit sifrit [Assimilation of an online instructional culture in schools]. In D. Chen \& G. Kurtz (Eds.), ICT, learning and teaching (pp. 371-400). The Center for Academic Studies.

Shonfeld, M. (2017). Lemida shitufit ba'idan ha'digitali [Collaboration in learning]. In O. Goldstein and U. Melamed. (Eds.), Pedagogy in the digital age (pp.187-216). Kalil.

Shonfeld, M., \& Gibson, D. (Eds.). (2019). Collaborative learning in a global world. Information Age Publishing. 
Shonfeld, M., Hoter, E., \& Ganayem, A. (2013). Connecting cultures in conflict through ICT in Israel. In R. S. P. Austin \& W. J. Hunter (Eds.), Online learning and community cohesion: Linking schools, (pp. 42-58). Routledge.

Shonfeld, M., \& Resta, P. (2019). Competitive game effect on collaborative learning in a virtual world. In M. Shonfeld \& D. Gibson (Eds.), Collaborative learning in a global world (pp. 91-110). Information Age Publishing.

Sleeman, J., Lang, C., \& Dakich, E. (2019). International students' transition to university: Connection and disconnection in online group work interactions. Student Success, 10(2), 35-45. https://doi.org/10.5204/ssj.v10i2.1300

So, H. J., \& Brush, T. A. (2008). Student perceptions of collaborative learning, social presence and satisfaction in a blended learning environment: Relationships and critical factors. Computers \& Education, 51(1), 318-336. https://doi.org/10.1016/j.compedu.2007.05.009

Tseng, H., Wang, C., Ku, H., \& Sun, L. (2009). Key factors in online collaboration and their relationship to teamwork satisfaction. Quarterly Review of Distance Education, 10(2), 195-206.

Tsuei, M. (2011). Development of a peer-assisted learning strategy in computer-supported collaborative learning environments for elementary school students. British Journal of Educational Technology, 42(2), 214-232. https://doi.org/10.1111/j.1467-8535.2009.01006.x

Tüzün, H., Bilgiç, H. G., \& Elçi, S. Y. (2019). The effects of 3D multi-user virtual environments on collaborative learning and social presence. International Electronic Journal of Elementary Education, 11(3), 221-231. https://doi.org/10.26822/iejee.2019349247

Wang, D. Y., Lin, S. S., \& Sun, C. T. (2007). DIANA: A computer-supported heterogeneous grouping system for teachers to conduct successful small learning groups. Computers in Human Behavior, 23(4), 1997-2010. https://doi.org/10.1016/j.chb.2006.02.008

Wang, J. L., Jackson, L. A., Zhang, D. J., \& Su, Z. Q. (2012). The relationships among the Big Five personality factors, self-esteem, narcissism, and sensation-seeking to Chinese university students' uses of social networking sites (SNSs). Computers in Human Behavior, 28(6), 2313-2319. https://doi.org/10.1016/j.chb.2012.07.001

Waters, L. H., \& Napier, W. (2002). Building and supporting student team collaboration in the virtual classroom. Quarterly Review of Distance Education, 3(3), 345-352.

Weinberger, Y., \& Shonfeld, M. (2020). Students' willingness to practice collaborative learning. Teaching Education, 31(2), 127-143. https://doi.org/10.1080/10476210.2018.1508280

Zhang, X., Chen, G., \& Xu, B. (2020). The influence of group big-five personality composition on student engagement in online discussion. International Journal of Information and Education Technology, 10(10). https://doi.org/10.18178/ijiet.2020.10.10.1452

Zhou, J. (2017). Exploring the factors affecting learners' continuance intention of MOOCs for online collaborative learning: An extended ECM perspective. Australasian Journal of Educational Technology, 33(5), 123-135. https://doi.org/10.14742/ajet.2914

Zhu, C. (2012). Student satisfaction, performance, and knowledge construction in online collaborative learning. Journal of Educational Technology \& Society, 15(1), 127-136. https://drive.google.com/file/d/14vwuvBYezch5WpVG-3kVmAmO7cMoUruE/view

Zygouris-Coe, V. I. (2019). Benefits and challenges of collaborative learning in online teacher education. In T. L. Heafner, R. Hartshrone, \& R. Thripp (Eds.), Handbook of research on emerging practices and methods for K-12 online and blended learning (pp. 33-56). IGI Global. https://www.igiglobal.com/chapter/benefits-and-challenges-of-collaborative-learning-in-online-teachereducation/223605

Corresponding author: M. Shonfeld, mirish@macam.ac.il

Copyright: Articles published in the Australasian Journal of Educational Technology (AJET) are available under Creative Commons Attribution Non-Commercial No Derivatives Licence (CC BY-NC-ND 4.0). Authors retain copyright in their work and grant AJET right of first publication under CC BY-NC-ND 4.0 .

Please cite as: Shonfeld, M. (2021). Factors affecting student-teacher satisfaction with a multi-college online collaborative course. Australasian Journal of Educational Technology, 37(6), 193-205. https://doi.org/10.14742/ajet.6073 